\title{
Control and supervision of a solar electric system
}

\author{
Benabed Khadidja $^{1}$, Boudghene Stambouli Amine ${ }^{2}$, Benabadji Noureddine ${ }^{3}$ \\ ${ }^{1,2}$ Département d'Electronique, Université des Sciences et de la Technologie d'Oran Mohamed Boudiaf, USTO-MB, BP \\ 1505, El M'naouer, 31000 Oran Algérie \\ ${ }^{3}$ Laboratoire d'Analyse et d'Application des Rayonnements (LAAR), Université des Sciences et de la Technologie \\ d'Oran Mohamed Boudiaf, USTO-MB, BP 1505, El M'naouer, 31000 Oran Algérie
}

\begin{tabular}{|c|c|}
\hline Article Info & ABSTRACT \\
\hline Article history: & \multirow{5}{*}{$\begin{array}{l}\text { Energy consumption is one of the biggest concerns because it is increasing } \\
\text { and it has a great impact on our environment. Photovoltaic energy is a } \\
\text { possible response to the challenges of the energy transition of tomorrow. For } \\
\text { proper operation, the solar photovoltaic system needs a rigorous supervision } \\
\text { of its electrical and physical parameters. Monitoring is one of the foundations } \\
\text { of photovoltaic maintenance engineering. This article describes the design } \\
\text { and realization of a solar monitor for the monitoring of the correct operation } \\
\text { of a mini power plant from panels photovoltaic. }\end{array}$} \\
\hline Received Jan 14, 2019 & \\
\hline Revised Mar 1, 2019 & \\
\hline Accepted Jul 24, 2019 & \\
\hline & \\
\hline
\end{tabular}

Microcontroller

Monitor

Photovoltaic system

Solar energy

Supervision

Copyright (C) 2019 Institute of Advanced Engineering and Science. All rights reserved.

\section{Corresponding Author:}

Benabed Khadidja,

Département d'Electronique,

Université des Sciences et de la Technologie d'Oran Mohamed Boudiaf,

BP 1505, El M'naouer, 31000 Oran Algérie.

Email: Khadidja.benabed@univ-usto.dz

\section{INTRODUCTION}

Solar energy is playing major role as an important renewable energy source due to its cleanness, zero cost and everywhere availability [1]. Photovoltaic technology has advanced and made solar panels more flexible and easier to install [2].

The supervision of a photovoltaic system, or monitoring, makes it possible to evaluate the operation quality of the system and on the other hand to detect any anomalies. It is generally composed of a data acquisition and storage system, a signal processing or analysis software, and a display. The supervising system is a solution for limit production losses and improves solar plant performance [3]. Grace an alert system, fault analysis is possible to reduce the cost of maintenance and avoid unnecessary travel [4]. There are many systems for evaluating the performance of a photovoltaic system [5]-[9]. Some systems allow, for example, the comparison between the actual production of an installation and the theoretical production. An alert is sent to the user warning of an anomaly on the PV system. This article describes the design and construction of a solar monitor for the supervision and control of a PV solar system.

\section{MATERIAL AND METHODS}

The realized device is dedicated for $6 \mathrm{~V}$ or $12 \mathrm{~V}$ photovoltaic panels system at a medium power (up to $50 \mathrm{~W}$ ). It is responsible for performing automatic and periodic measurements of five important physical parameters to be monitored: the charging current of the energy accumulator (battery), the discharge current, the charging voltage, the external temperature (close to P.V.) and the internal temperature (close to battery) (Figure 1). 


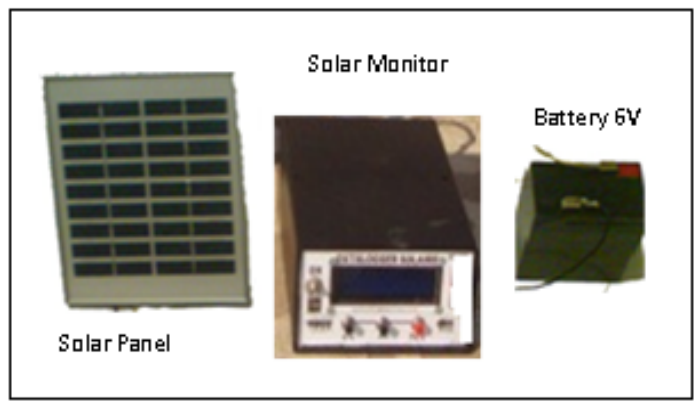

Figure 1. System overview

\section{HARDWARE DESCRIPTION}

The diagram in the figure 2 shows the main modules of this device: an 8-bit microcontroller (PIC18F452), a 2x16 characters LCD display module and the regulated power section.

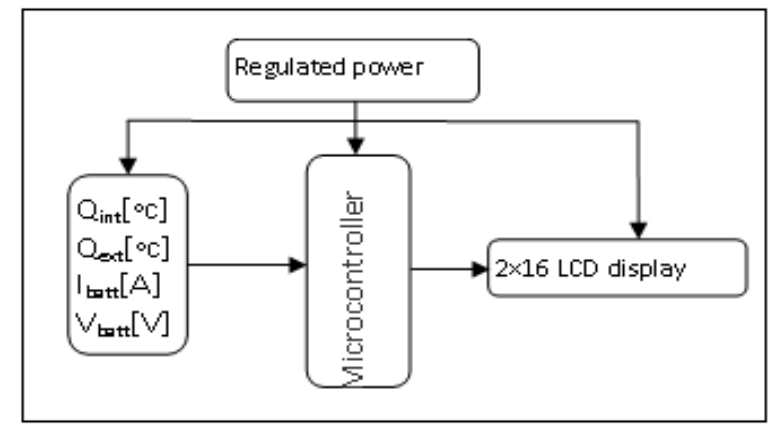

Figure 2. Block diagram of the prototype device.

\subsection{The 8-bits microcontroller pic $\mathbf{1 8 f} 452$}

It is a microcontroller of the high-end range of the American company Microchip, a world leader in this category of programmable digital components. It is equipped with a RISC architecture, whose performances in speed and memory usage are much better than the old CISC architecture [10]. The PIC is powered by a voltage of $5 \mathrm{~V}$. The resistor R0 has been added to lower the current on the MCLR pin. The diode D0 is added to prevent high voltage Vpp (13V) goes to Vdd when doing In-Circuit Programming of the microcontroller. The LED indicates the presence of power in the monitor (Figure 3). Capacitor C0 filters any transient voltage or noise that could crash the system.

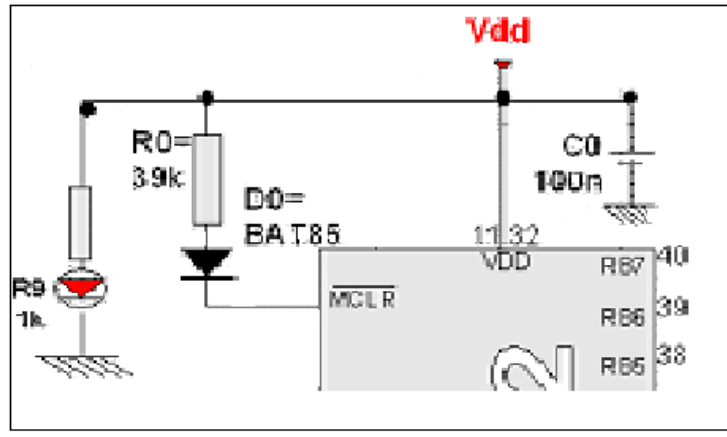

Figure 3. Electrical diagram of the PIC power supply.

\subsection{The regulated power supply section}

Control and supervision of a solar electric system (Benabed Khadidja) 
The regulator used is a classic regulator 78L05, low power version (max. output current $=100 \mathrm{~mA})$. A Schottky diode BAT85 has been added to bias this 78L05 regulator, in order to slightly increase the supply voltage $\mathrm{Vdd}$ to $+5.12 \mathrm{~V}$. This particular value allows us to round the measurement sensitivity precisely to 5 $\mathrm{mV}$, instead of $4.88 \mathrm{mV}$ if we kept $\mathrm{Vdd}=5 \mathrm{~V}$, which greatly simplifies the programming subroutine of data acquisition. The two capacitors $\mathrm{C} 3, \mathrm{C} 4$ are placed at each side of the regulator to smooth the voltage in case of sudden transient higher consumption that could occur in long wiring when connecting P.V. panel to the microcontroller board (Figure 4).

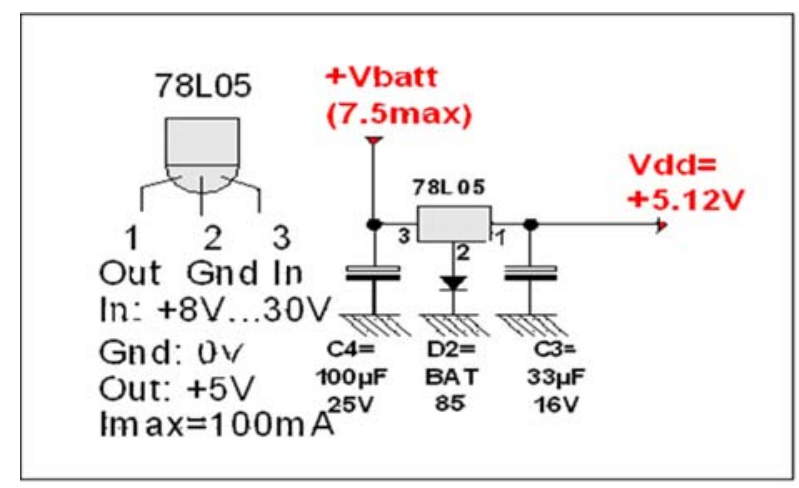

Figure 4. The Regulated power supply.

\subsection{The LCD display module $2 \times 16$ characters}

A $2 \times 16$ character LCD display module requires at least $10 \mathrm{I} / \mathrm{O}$ lines (Inputs / outputs) from the PIC, in 8-bit mode, or only $6 \mathrm{I} / \mathrm{O}$ lines in 4-bit mode [11]. The LCD display is powered by a voltage of $5 \mathrm{~V}+/-5 \%$. To save the input / output ports of the PIC, the LCD module will operate in 4-bit mode (4 data bits) instead of 8 (LCD module configuration at initialization), and only in write mode (pin RW connected to the ground). The contrast control can be adjusted using the potentiometer Aj1(figure 5).

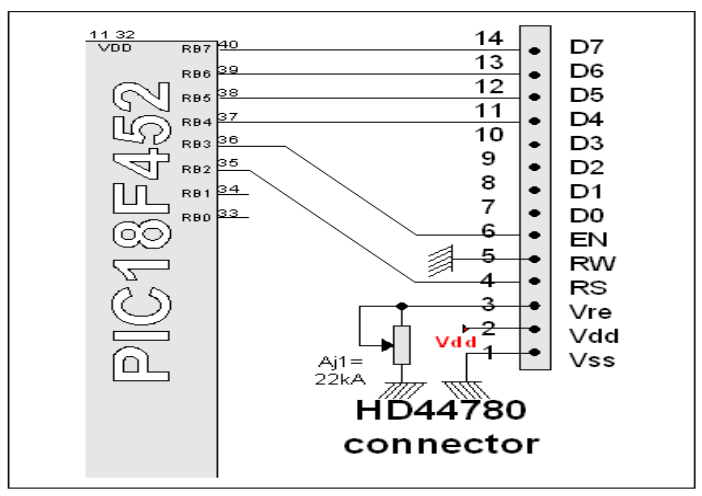

Fig. 5. The 2x16 LCD display module.

\subsection{The temperature sensor supply}

The temperature sensor is a LM35DZ that can measure a temperature between 0 and $+100{ }^{\circ} \mathrm{C}$; it provides a voltage proportional to the temperature with a resolution of $10 \mathrm{mV} /{ }^{\circ} \mathrm{C}$ [12]. The LM35DZ temperature sensor can be powered in a range of 4 to $20 \mathrm{~V}$ with an internal consumption of less than $60 \mu \mathrm{A}$ at $4 \mathrm{~V}$. For our internal temperature sensor, the regulated power supply Vdd has been used, while for the external one, we directly used the $6 \mathrm{~V}$ photovoltaic panel. In the absence of the sunshine, it is powered directly by the battery. Resistor R7 and capacitor C6 (for the external temperature sensor) act as a series RC

Int J Pow Elec \& Dri Syst Vol. 10, No. 4, Dec 2019 : 2096 - 2100 
damper to improve the tolerance of long wires capacitance (PV panel are mounted far from the microcontroller board) (Figure 6 and Figure 7).

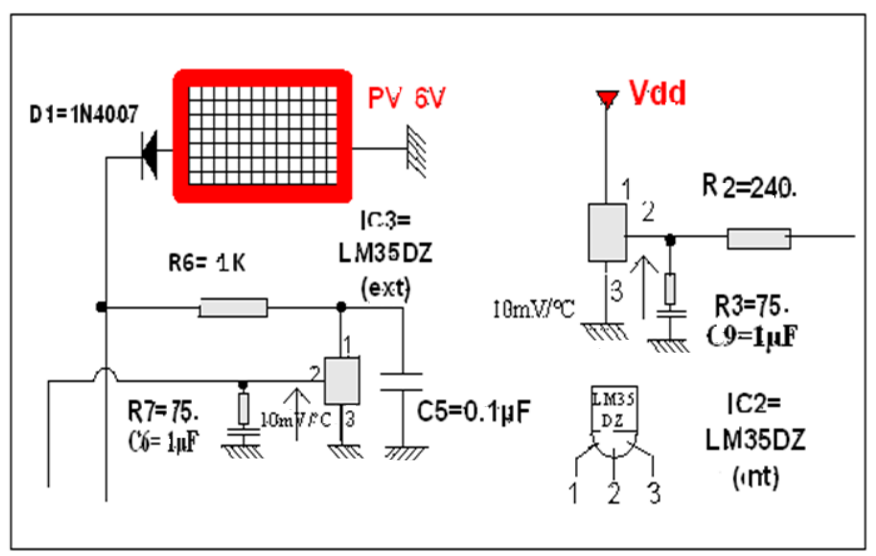

Figure 6. Diagram of the internal and external temperature sensors.

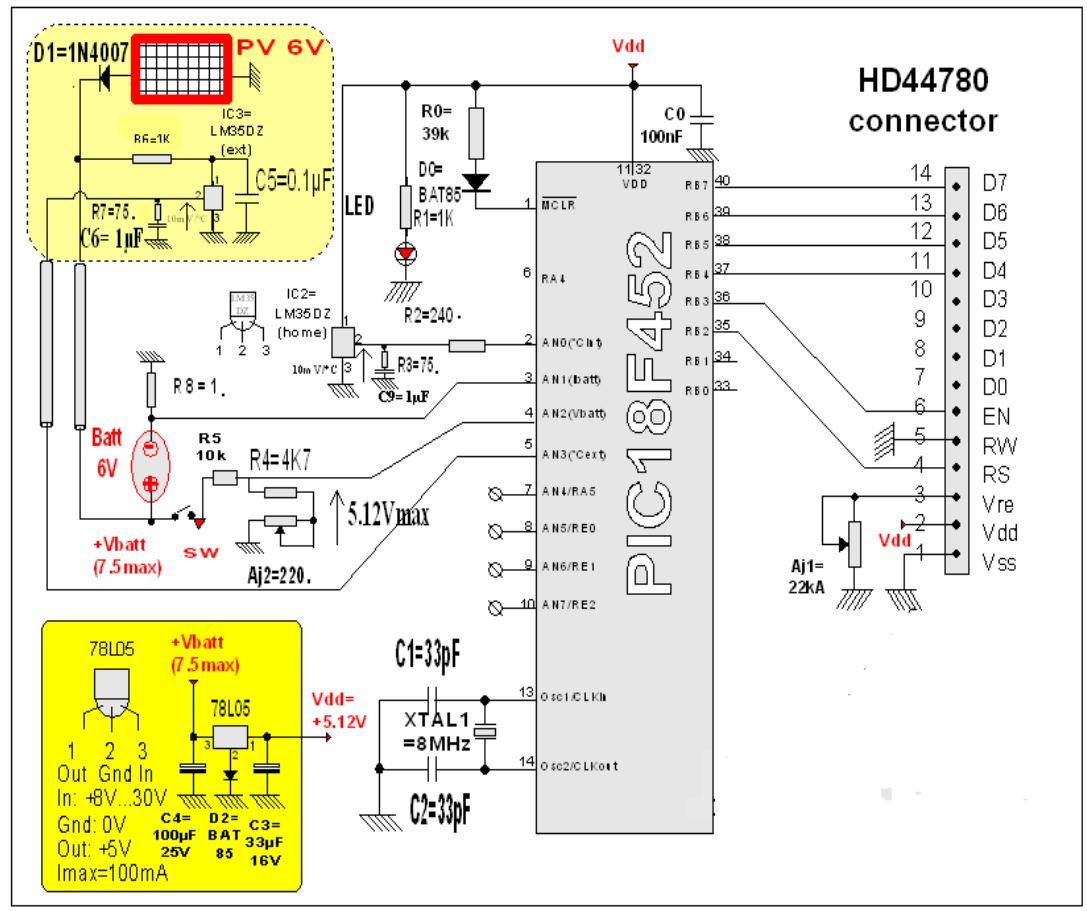

Figure 7. Complete electrical circuit diagram.

\section{RESULTS AND DISCUSSIONS}

This solar monitor is responsible for performing automatic and periodic measurements of important physical parameters be monitored. It offers information about internal and external temperature, the current and voltage involved between the P.V. panels system and the energy storage system (Figure 8).This device uses few components, readily available and a very low cost. 


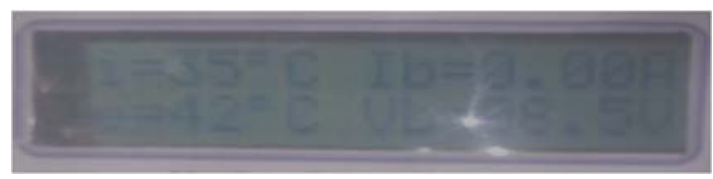

Figure 8 . The display of the four measured parameters.

\section{CONCLUSION}

This paper describes the design and implementation of an automatic recording device (solar monitor) to measure several important physical parameters (internal and external temperature, the current and voltage involved between the P.V. panels system and the energy storage system). This prototype uses few components, readily available and provides a good reliability. It is recommended in the management and the monitoring of a low cost operational solar power plant based on photovoltaic panels.

\section{REFERENCES}

[1] H. A. Attia,"High performance PV system based on artificial neural network MPPT with PI controller for direct current water pump applications, "International Journal of Power Electronics and Drive System (IJPEDS), Vol. 10, pp. 1329-1338, 2019.

[2] A. Mezouari, R. Elgouri, M. Igouzal, M. Alareqi, K. Mateur, H. Dahou, L. Hlou,“ A New Photovoltaic Energy Sharing System between Homes in Standalone Areas, "International Journal of Electrical and Computer Engineering, Vol. 8, pp. 4855-4862, 2018.

[3] A. Chouder, S. Silvestre, "Automatic supervision and fault detection of PV systems based on power losses analysis, "Energy Conversion and Management, vol.51, pp.1929-1937, 2010.

[4] U. Anliker, J. A. Ward, P. Lukowicz, G. Tröster, F. Dolveck, M. Baer, F. Keita, E. B. Schenker, F. Catarsi, L. Coluccini, A. Belardinelli, D. Shklarski, M. Alon, E. Hirt, R. Schmid, M. "Vuskovic, AMON: A Wearable Multiparameter Medical Monitoring and Alert System," IEEE Transactions On Information Technology In Biomedicine, Vol. 8, pp.415-427, 2004.

[5] M. Hashem Nehrir, J. Brock LaMeres, G. Venkataramanan, V. Gerez, L. A. Alvarado, "An Approach to Evaluate the General Performance of Stand-Alone Wind/Photovoltaic Generating Systems," IEEE Transactions on Energy Conversion, Vol. 15, pp.433-439, 2000.

[6] B. J. Huang, T. H. Lin, W. C. Hung, F. S. Sun, "Performance Evaluation Of Solar Photovoltaic/Thermal Systems," Solar Energy, Vol. 70, pp.443-448, 2001

[7] J. Andrés, C. Castro, A. Julián, A. Cardona ,"Model to Evaluate the Performance of Building Integrated Photovoltaic Systems using Matlab/Simulink," International Journal of Electrical and Computer Engineering (IJECE), Vol.8, pp. 680-688, 2018.

[8] M.A. Elhadidy, "Performance evaluation of hybrid (wind/ solar/ diesel) power systems," Renewable Energy, Vol. 26, pp. 401-413, 2002.

[9] A. Abdulmula, K. Sopian, L. Chin Haw, A. Fazlizan, "Performance evaluation of standalone double axis solar tracking system with maximum light detection MLD for telecommunication towers in Malaysia," International Journal of Power Electronics and Drive System (IJPEDS), Vol. 10, pp. 444-453, 2019.

[10] S.Kumaravel, P. Neelamegam, R.Vasumathi, "Distributed Chloride Prediction System Using Neural Network and PIC18F452 Microcontrollers in Water Analysis," International Journal of Computer Applications, Vol. 8, pp.1520, 2010.

[11] K.Benabed, S.A.Boudghene, N.Benabadji,"Prototyping a Dedicated Photovoltaic System Datalogger," TELKOMNIKA Indonesian Journal of Electrical Engineering, Vol.16, pp. 488-494, 2015.

[12] L.Messikh, S.Chikhi, F. Chikhi, T., "Chergui, Mise au point d'un régulateur de charge/décharge de batterie avec seuils adaptatifs de tension pour les applications photovoltaïques", Revue des Energies Renouvelables, Vol. 11, pp. 281-290, 2008.

Int J Pow Elec \& Dri Syst Vol. 10, No. 4, Dec 2019 : 2096 - 2100 